\title{
Frequency of TERT Promoter Mutations in Prostate Cancer
}

\author{
Robert Stoehr $^{\mathrm{a}}$ Helge Taubert ${ }^{\mathrm{b}} \quad$ Ulrike Zinnall $^{\mathrm{a}} \quad$ Johannes Giedl ${ }^{\mathrm{a}}$ \\ Nadine T. Gaisa ${ }^{c}$ Maximilian Burger ${ }^{d}$ Petra Ruemmele ${ }^{e}$ Carolyn D. Hurst $^{f}$ \\ Margaret A. Knowles ${ }^{f}$ Bernd Wullich $^{b}$ Arndt Hartmann ${ }^{a}$ \\ a Institute of Pathology and ${ }^{b}$ Department of Urology, University Hospital Erlangen, Friedrich-Alexander-University \\ Erlangen-Nuremberg, Erlangen, ' Institute of Pathology, RWTH Aachen University, Aachen, dDepartment of Urology, \\ Caritas St. Josef Medical Center and ' Institute of Pathology, University of Regensburg, Regensburg, Germany; \\ fSection of Experimental Oncology, Leeds Institute of Cancer and Pathology, University of Leeds, St. James's \\ University Hospital, Leeds, UK
}

\section{Key Words}

TERT · Promoter · Mutation · SNaPshot analysis .

Sanger sequencing $\cdot$ Prostate cancer

\begin{abstract}
Objective: Recently, recurrent mutations within the core promoter of the human telomerase reverse transcriptase (TERT) gene generating consensus binding sites for ETS transcription factor family members were described in melanomas and other malignancies (e.g. bladder cancer, hepatocellular carcinoma). These mutations were discussed as early drivers for malignant transformation. In prostate cancer (PrCa) TERT expression has been associated with a poor prognosis and higher risk for disease recurrence. The underlying mechanisms for high TERT expression in PrCa have still not been clarified. To date, data on TERT promoter mutation analysis in $\mathrm{PrCa}$ are sparse. Therefore, we performed sequence analysis of the core promoter region of the TERT gene in an unselected cohort of prostate tumors. Methods: Sections from 167 formalin-fixed, paraffin-embedded and cryopreserved prostate tumors were microdissected and used for DNA isolation. The mutation hotspot region within
\end{abstract}

(c) 2015 S. Karger AG, Basel

$1015-2008 / 15 / 0822-0053 \$ 39.50 / 0$ the TERT core promoter ( -260 to +60 ) was analyzed by direct Sanger sequencing or SNaPshot analysis. Results: All cases were analyzed successfully. Mutations within the core promoter of the TERT gene were not detected in any of the cases with all tumors exhibiting a wild-type sequence. Conclusion: TERT core promoter mutations reported from several other malignancies were not detected in our unselected cohort of PrCa. These data indicate that alterations within the core promoter of the TERT gene do not play an important role in prostate carcinogenesis.

ㄷ) 2015 S. Karger AG, Basel

\section{Introduction}

The search for recurrent mutations in single genes within tumor genomes is driven by the hope of uncovering important driver alterations that lead to a better understanding of carcinogenesis. The availability of new and sensitive high-throughput sequencing technologies sped up this search and led to the identification of new mutation hotspots in a variety of cancer entities. Although a new definition of a recurrent gene mutation was 
suggested in terms of combining recurrent alterations on the scale of a pathway rather than only one single gene, discovering new recurrent gene mutations is still a worthwhile approach in cancer research [1].

Recently, mutations within the promoter of the telomerase reverse transcriptase (TERT) gene that encodes the catalytic subunit of the telomerase were identified in familial and sporadic melanoma with a high frequency [2]. The immortality of cells is still a classical hallmark of tumors and reactivation of telomerase leading to telomere maintenance remains a fundamental process in carcinogenesis. Alterations within the coding region of the TERT gene are a rare event in cancers. Therefore, the identification of recurrent mutations within the core promoter of the TERT gene leading to new binding motifs for transcription factors of the ETS family attracted great interest among the cancer research field [3]. The consequences of these mutations are still not completely understood but they lead to a 2- to 4-fold increased transcriptional activity in vitro [4]. Subsequently, these mutations were found in several other malignancies, e.g. bladder carcinoma, thyroid cancer or cancers of the nervous system, and were discussed as early drivers for malignant transformation [3].

Expression and reactivation of telomerase has also been described as an important feature of prostate cancer (PrCa). Telomerase activity was found in up to $100 \%$ of analyzed PrCa cases [5]. Interestingly, high expression of telomerase components does not always result in mandatory telomerase activity [6]. In addition, a significant association between TERT expression and aggressive behavior of prostate tumors has been reported [7]. Recently, promising in vitro data were published showing telomerase as an important target of an antiandrogen therapy for $\mathrm{PrCa}$, and the usefulness of boron derivatives as a telomerase inhibitor in $\mathrm{PrCa}$ cells $[8,9]$. These data suggest telomerase inhibition as a reasonable therapeutic approach for the treatment of PrCa. The molecular and cellular pathways involved in telomerase reactivation in PrCa are still not clear. Expression of TERT and the activity of telomerase were shown to be regulated by androgen receptor (AR) signaling whereas exogenous expression of AR surprisingly led to inhibition of TERT transcription in $\mathrm{PrCa}$ cells $[10,11]$. The genomic region of the TERT gene (chromosome $5 \mathrm{p} 15.33$ ) was not described as a region containing copy number alterations in prostate tumors, making gene amplification as a mechanism for TERT expression in PrCa unlikely [12]. Less is known about TERT promoter mutations in PrCa. To date only three studies with a combined number of 49 prostate tu-
Table 1. Characteristics of the study patients

\begin{tabular}{ll}
\hline PrCa cases, $\mathrm{n}$ & 167 \\
Age, years & \\
$\quad$ Range & $46-87$ \\
Median & 66 \\
$\quad$ Mean & $64.9 \pm 6.7$ \\
Stage, $\mathrm{n}$ & \\
$\quad$ Organ-confined disease & 76 \\
$\quad$ Non-organ-confined disease & 89 \\
$\quad$ No data available & 2 \\
Gleason score & \\
$\quad$ Range & $3-10$ \\
$\quad$ Median & 7 \\
Gleason sum, n & \\
$\quad<7$ & 52 \\
7 & 54 \\
$>7$ & 54 \\
No data available & 7 \\
\hline
\end{tabular}

mors have reported sequence analysis of the TERT promoter and found no evidence for involvement of TERT promoter mutations in PrCa [13-15]. These data already indicate that the cellular mechanisms of telomerase reactivation in PrCa are only poorly understood and further clarification is needed. As TERT promoter mutations are a potential mechanism for a possible telomerase reactivation we wanted to further the discussion of this topic for PrCa. We therefore analyzed the core promoter region of the TERT gene containing the reported mutation hotspots in the largest series of PrCa examined to date.

\section{Materials and Methods}

Patients and Tissue Samples

Overall, 167 unselected, archival prostate tumors (formalinfixed and paraffin-embedded tissue samples, $\mathrm{n}=119$; snap-frozen tissue samples, $n=48$ ) were investigated. All patients were Caucasians. The tumors were diagnosed according to the WHO classification of prostate tumors and staged according to the TNM system $[16,17]$. The characteristics of the study participants are shown in table 1. Prior institutional review board (University Hospital Erlangen) approval was obtained for molecular analysis on archival material.

\section{Tissue Microdissection and DNA Isolation}

DNA was extracted from prostate tumors after precise manual microdissection (purity of tumor cells $>85 \%$ ) of serial sections $(5 \mu \mathrm{m})$ using the High Pure PCR Template Preparation Kit (Roche $\mathrm{GmbH}$, Mannheim, Germany) according to the manufacturer's instructions. DNA quality and quantity was determined using the Synergy 2 Multi-Detection Reader (BioTek, Bad Friedrichshall, Germany) according to the manufacturer's instructions.
Stoehr et al. 


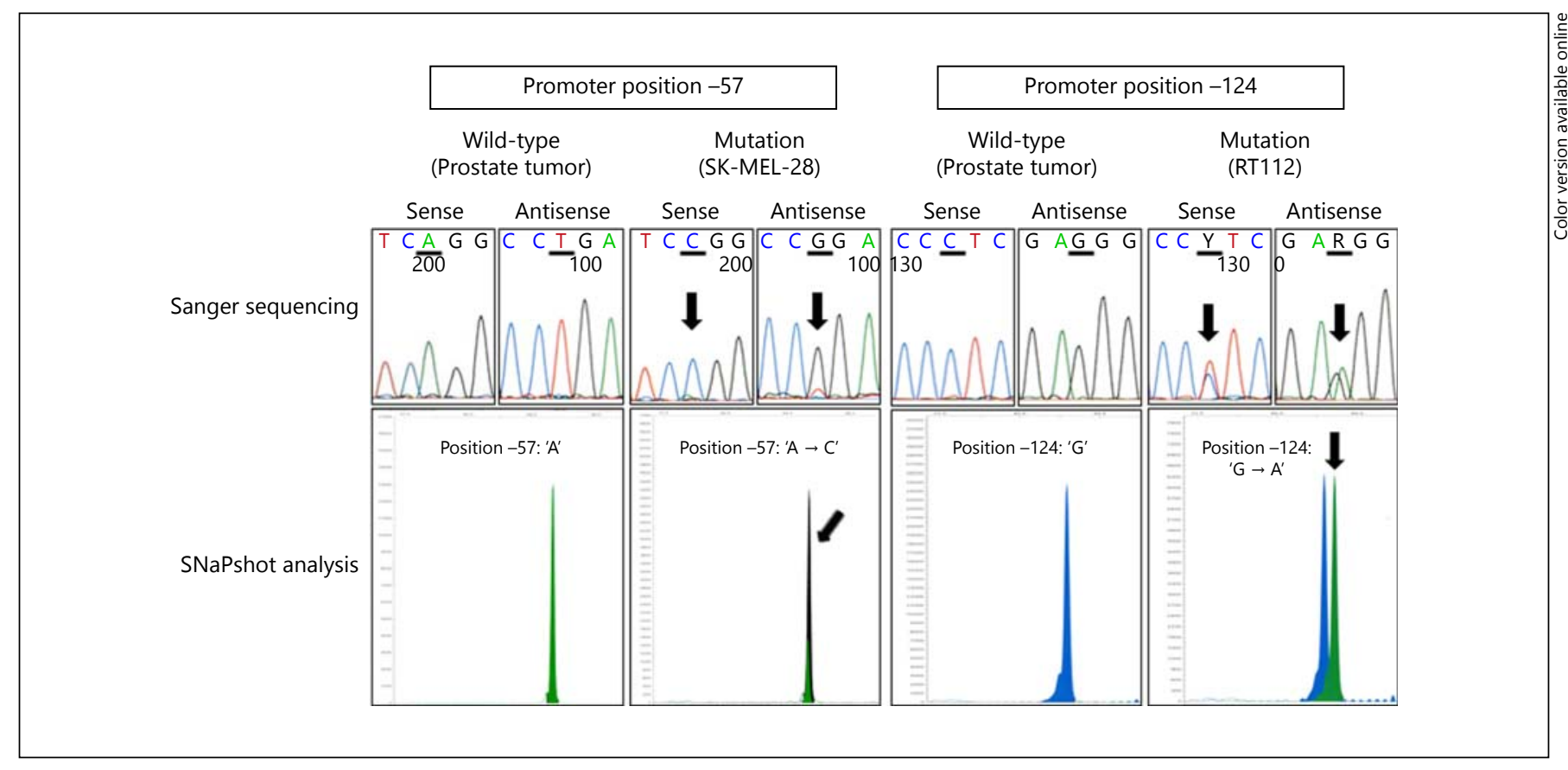

Fig. 1. Representative examples for Sanger sequencing and $\mathrm{SNaPshot}$ analysis of the promoter mutation hotspots at -57 and -124. Upper lane: Sanger sequencing of DNA from a prostate tumor showing a wild-type sequence for TERT promoter position $-57(\mathrm{~A})$ and position $-124(\mathrm{G})$. DNA from the melanoma

\section{TERT Promoter Analysis Using Sanger Sequencing}

A region of the core promoter $(-260$ to +60$)$ of the TERT gene containing the described mutation hotspots was amplified by PCR using primers (sense: $5^{\prime}$ - att cgc ggg cac aga cgc $-3^{\prime}$; antisense: $5^{\prime}$ - tcg cgg tag tgg ctg cgc $-3^{\prime}$ ) obtained from Metabion (Martinsried, Germany) in a total volume of $25 \mu$ l containing approximately $150 \mathrm{ng}$ DNA, $0.2 \mathrm{mM}$ dNTP (Promega, Mannheim, Germany), $0.18 \mu \mathrm{M}$ primers, 5\% DMSO and $0.0025 \mathrm{U} / \mu \mathrm{l}$ GoTaq (Promega). The thermal cycling conditions were as follows: initial denaturation for $3 \mathrm{~min}$ at $95^{\circ} \mathrm{C}, 45$ cycles of denaturation at $94^{\circ} \mathrm{C}$ for $1 \mathrm{~min}$, annealing at $69.3^{\circ} \mathrm{C}$ for $1 \mathrm{~min}$, elongation at $72^{\circ} \mathrm{C}$ for $1 \mathrm{~min}$ and final primer extension at $72^{\circ} \mathrm{C}$ for $10 \mathrm{~min}$. Gradient PCR was used for the optimization of cycling conditions. After amplification, $\mathrm{PCR}$ products (size $335 \mathrm{bp}$ ) were purified using the Qiagen Dye Ex 2.0 ${ }^{\mathrm{TM}}$ Spin Kit according to the manufacturer's conditions. Sequence analysis was performed with PCR primers using a Big Dye Terminator v.1.1 Cycle Sequencing Kit and an ABI 3500 Genetic Analyzer (both Applied Biosystems, Foster City, Calif., USA).

\section{TERT Promoter Analysis Using SNaPshot Analysis}

A previously reported SNaPshot assay (Life Technologies Corp., Carlsbad, Calif., USA) was used for the detection of hotspot mutations at positions $-57,-124$ and -146 . Capillary electrophoresis and detection of fluorescence-labeled products were performed using an Applied Biosystems ABI 3500 Genetic Analyzer. A detailed description of the method can be found elsewhere [18].

TERT Promoter Mutations in PrCa cell line SK-MEL-28 showing 'A $\rightarrow$ C' mutation at position -57 . DNA from the bladder cancer cell line RT112 showing ' $G \rightarrow$ A' mutation at position -124. Lower lane: corresponding SNaPshot analyses. Arrows indicate mutations in the promoter sequence.

\section{Cell Lines Used as Positive Controls for TERT Mutation}

Analysis

The malignant melanoma cell line SK-MEL28 derived form a 51-year-old male patient was kindly donated by Prof. Dr. A. Bosserhoff (Institute of Biochemistry and Molecular Medicine, FAU Erlangen-Nuremberg, Germany). SK-MEL28 cells showed a $-57 \mathrm{~A} \rightarrow \mathrm{C}$ mutation of the TERT promoter. The urothelial carcinoma cell line RT112 derived from a female patient with a transitional cell carcinoma of the urinary bladder was purchased from the German collection of microorganisms and cell cultures (Leibniz Institute DMSZ, Braunschweig, Germany). RT112 cells harbor a $-124 \mathrm{C} \rightarrow \mathrm{T}$ mutation of the TERT promoter [4].

\section{Results}

Analysis of previously reported mutation hotspots within the core promoter of the TERT gene was successfully performed in all available cases. Mutation analysis using Sanger sequencing could be performed in 108/167 cases (fig. 1). In 59/167 cases the core promoter region could not be amplified due to insufficient DNA quality (e.g. DNA degradation, low DNA concentration). In these cases SNaPshot analysis of mutation sites at -57 , 
-124 and -146 was performed (fig. 1). Promoter mutations were not detected in any of the samples with all cases exhibiting a wild-type sequence.

\section{Discussion}

In the present study we performed sequence analysis of the core promoter region of the TERT gene in a cohort of 167 PrCa samples. The results of our study suggest that TERT promoter mutations are not involved in the development of PrCa as no mutations were detected in any of the investigated cases. These data are in line with previously published studies on only very small cohorts and corroborate the minor importance of TERT promoter alterations in $\mathrm{PrCa}$ [13-15]. Meanwhile, a study investigating the whole genomes of $57 \mathrm{PrCa}$ cases has been published [19]. Apart from already known data from exome analyses, this study displayed the spectrum of whole-genome alterations in prostate tumors. Here only one TERT missense mutation was detected (p.R819C) but no promoter mutations were reported. This study also strengthens our findings and should, together with our data, finalize the discussion on TERT mutations in PrCa.

There are several lines of evidence that genomic variations but not mutation might influence TERT expression and disease risk in PrCa. In a large case-control study an intronic single nucleotide polymorphism (SNP) in the TERT gene (rs2242652, C $8992 \mathrm{~T}$ ) was found that was strongly associated with increased PrCa risk. Because of this strong correlation it was suggested that the SNP might have a functional relevance. Indeed, further evaluation showed increased TERT expression associated with the presence of SNP variants in benign prostate tissue from patients who underwent radical prostatectomy $[20,21]$. This increased TERT expression might provide a possible predisposition for PrCa. Another influence on TERT expression might be length polymorphisms in variable number tandem repeats (VNTRs). Recently, it was shown that the TERT gene contains five VNTRs that are located within introns 2 and 6. A large case-control study found a significantly higher PrCa risk for individuals carrying rare VNTR2-2nd alleles than for individuals with common alleles. These VNTRs were also discussed as having an enhancer function for gene transcription. In vitro studies on PrCa cell lines analyzing the activity of the TERT promoter in combination with different VNTR variants clearly showed an increased luciferase activity for the VNTR2-2nd variants $[22,23]$. These effects might also be expected for TERT expression and could also increase the individual risk for PrCa.

Besides these genomic influences, TERT expression is also regulated by several cellular processes in PrCa. Matsumura et al. [24] analyzed the impact of the phosphorylation status of Fas-associated death domain-containing protein (FADD) on TERT expression in PrCa. FADD has a crucial role in the formation of the death-inducing signaling complex and is also involved in cell cycle regulation. The phosphorylated form of FADD was highly expressed in PrCa with a lower Gleason score and was inversely associated with a shorter recurrence-free survival after prostatectomy. In parallel, cases with high levels of phosphorylated FADD also showed only low TERT expression, suggesting a direct influence of FADD phosphorylation on TERT expression. Shimada et al. [25] found significant differences between FADD phosphorylation levels and clinicopathological outcomes for Gleason scores $3+4$ and $4+3$. These data indicate that Gleason $4+3$ tumors should be considered as high-risk tumors and stimulating agents that drive transition from nonphosphorylated to phosphorylated FADD (e.g. paclitaxel) might be considered as therapeutic options. High TERT expression correlates with aggressive PrCa levels of TERT and nonphosphorylated FADD, which might represent potent biomarkers for the biological behavior of PrCa. Furthermore, different factors can regulate TERT expression positively or negatively. Several transcription factors (e.g. SP1), hormones (e.g. androgen) and the PI3K/Akt and MAP kinase pathways can upregulate TERT transcription [reviewed in 26]. In addition, the downregulation of TERT by six microRNAs (let-7g*, miR-133a, miR-138-5p, miR-342-5p, miR-491-5p and miR-541-3p) has recently been reported [27].

In summary, high expression of TERT is unlikely to be caused by promoter mutations or other genomic alterations in PrCa. TERT expression is more likely influenced by diverse cellular pathways resulting in increased cell cycle activity and proliferation.

\section{Acknowledgements}

The authors thank Karina Dresel, Stefanie Herlein, Claudia Knoll, Nina Oks, Verena Popp and Katrin Weigelt for excellent technical assistance.

\section{Disclosure Statement}

The authors have no conflict of interest.
Stoehr et al. 


\section{References}

1 Babaei S, Hulsman M, Reinders M, de Ridder J: Detecting recurrent gene mutation in interaction network context using multi-scale graph diffusion. BMC Bioinformatics 2013; 14:29.

2 Horn S, Figl A, Rachakonda PS, Fischer C, Sucker A, Gast A, Kadel S, Moll I, Nagore E, Hemminki K, Schadendorf D, Kumar R: TERT promoter mutations in familial and sporadic melanoma. Science 2013;339:959961.

3 Vinagre J, Pinto V, Celestino R, Reis M, Populo $\mathrm{H}$, Boaventura $\mathrm{P}$, Melo M, Catarino T, Lima J, Lopes JM, Maximo V, Sobrinho-Simoes M, Soares P: Telomerase promoter mutations in cancer: an emerging molecular biomarker? Virchows Arch 2014;465:119-133.

4 Huang FW, Hodis E, Xu MJ, Kryukov GV, Chin L, Garraway LA: Highly recurrent TERT promoter mutations in human melanoma. Science 2013;339:957-959.

5 Meeker AK: Telomeres and telomerase in prostatic intraepithelial neoplasia and prostate cancer biology. Urol Oncol 2006;24:122130.

6 Kamradt J, Drosse C, Kalkbrenner S, Rohde V, Lensch R, Lehmann J, Fixemer T, Bonkhoff $\mathrm{H}$, Stoeckle M, Wullich B: Telomerase activity and telomerase subunit gene expression levels are not related in prostate cancer: a real-time quantification and in situ hybridization study. Lab Invest 2003;83:623-633.

7 de Kok JB, Verhaegh GW, Roelofs RW, Hessels D, Kiemeney LA, Aalders TW, Swinkels DW, Schalken JA: $D D 3^{P C A 3}$, a very sensitive and specific marker to detect prostate tumors. Cancer Res 2002;62:2695-2698.

8 Korkmaz M, Avci CB, Gunduz C, Aygunes D, Erbaykent-Tepedelen B: Disodium pentaborate decahydrate (DPD) induced apoptosis by decreasing hTERT enzyme activity and disrupting F-actin organization of prostate cancer cells. Tumour Biol 2014;35:15311538.

9 Liu S, Qi Y, Ge Y, Duplessis T, Rowan BG, Ip C, Cheng H, Rennie PS, Horikawa I, Lustig AJ, Yu Q, Zhang H, Dong Y: Telomerase as an important target of androgen signaling block- ade for prostate cancer treatment. Mol Cancer Ther 2010;9:2016-2025.

10 Guo C, Armbruster BN, Price DT, Counter CM: In vivo regulation of hTERT expression and telomerase activity by androgen. J Urol 2003;170:615-618.

11 Moehren U, Papaioannou M, Reeb CA, Grasselli A, Nanni S, Asim M, Roell D, Prade I, Farsetti A, Baniahmad A: Wild-type but not mutant androgen receptor inhibits expression of the hTERT telomerase subunit: a novel role of AR mutation for prostate cancer development. FASEB J 2008;22:1258-1267.

12 Williams JL, Greer PA, Squire JA: Recurrent copy number alterations in prostate cancer: an in silico meta-analysis of publicly available genomic data. Cancer Genet 2014;207:478488.

13 Killela PJ, Reitman ZJ, Jiao Y, et al: TERT promoter mutations occur frequently in gliomas and a subset of tumors derived from cells with low rates of self-renewal. Proc Natl Acad Sci U S A 2013;110:6021-6026.

14 Wu S, Huang P, Li C, Huang Y, Li X, Wang Y, Chen C, Lv Z, Tang A, Sun X, Lu J, Li W, Zhou J, Gui Y, Zhou F, Wang D, Cai Z: Telomerase reverse transcriptase gene promoter mutations help discern the origin of urogenital tumors: a genomic and molecular study. Eur Urol 2014;65:274-277.

15 Zheng X, Zhuge J, Bezerra SM, Faraj SF, Munari E, Fallon JT 3rd, Yang XJ, Argani P, Netto GJ, Zhong M: High frequency of TERT promoter mutation in small cell carcinoma of bladder, but not in small cell carcinoma of other origins. J Hematol Oncol 2014;7:47.

16 Epstein JI AF, Allsbrook WC, et al: Tumours of the prostate; in Eble JN Sauter G, Epstein JI, Sesterhenn IA: (eds): World Health Organization Classification of Tumours: Pathology and Genetics of Tumours of the Urinary System and Male Genital Organs, ed 1. Lyon, IARC, 2004.

17 Sobin LH WC: TNM Classification of Malignant Tumors, ed 6. New York, John Wiley and Sons, 2002.

18 Hurst CD, Platt FM, Knowles MA: Comprehensive mutation analysis of the TERT pro- moter in bladder cancer and detection of mutations in voided urine. Eur Urol 2014;65: 367-369.

19 Baca SC, Prandi D, Lawrence MS, et al: Punctuated evolution of prostate cancer genomes. Cell 2013;153:666-677.

20 Kote-Jarai Z, Saunders EJ, Leongamornlert DA, et al: Fine-mapping identifies multiple prostate cancer risk loci at $5 \mathrm{p} 15$, one of which associates with TERT expression. Hum Mol Genet 2013;22:2520-2528.

21 Kote-Jarai Z, Olama AA, Giles GG, et al: Seven prostate cancer susceptibility loci identified by a multi-stage genome-wide association study. Nat Genet 2011;43:785-791.

22 Yoon SL, Jung SI, Do EJ, Lee SR, Lee SY, Chu IS, Kim WJ, Jung J, Kim CS, Cheon SH, Leem SH: Short rare $h T E R T-V N T R 2-2^{\text {nd }}$ alleles are associated with prostate cancer susceptibility and influence gene expression. BMC Cancer 2010;10:393.

23 Leem SH, Londono-Vallejo JA, Kim JH, Bui H, Tubacher E, Solomon G, Park JE, Horikawa I, Kouprina N, Barrett JC, Larionov V: The human telomerase gene: complete genomic sequence and analysis of tandem repeat polymorphisms in intronic regions. Oncogene 2002;21:769-777.

24 Matsumura Y, Shimada K, Tanaka N, Fujimoto K, Hirao Y, Konishi N: Phosphorylation status of Fas-associated death domaincontaining protein regulates telomerase activity and strongly correlates with prostate cancer outcomes. Pathobiology 2009;76:293302 .

25 Shimada K, Matsuyoshi S, Nakamura M, Ishida E, Konishi N: Phosphorylation status of Fas-associated death domain-containing protein (FADD) is associated with prostate cancer progression. J Pathol 2005;206:423-432.

26 Daniel M, Peek GW, Tollefsbol TO: Regulation of the human catalytic subunit of telomerase (hTERT). Gene 2012;498:135-146.

27 Hrdlickova R, Nehyba J, Bargmann W, Bose HRJr: Multiple tumor suppressor microRNAs regulate telomerase and TCF7, an important transcriptional regulator of the Wnt pathway. PloS One 2014;9:e86990. 